\title{
Penggunaan Fasilitas E-Banking Dalam Minat Nasabah Studi Kasus Pada PT. BRI Syariah Kantor Cabang Pembantu Stabat
}

\author{
Asmawarna Sinaga ${ }^{1}$, Anjur Perkasa Alam ${ }^{2}$, Faisal Efendi ${ }^{3}$, Fajar Siddiq ${ }^{4}$ \\ 1,2,3,4Sekolah Tinggi Agama Islam Jam'iyah Mahmudiyah Tanjung Pura
}

Corresponding Author : anjurpohan@gmail.com

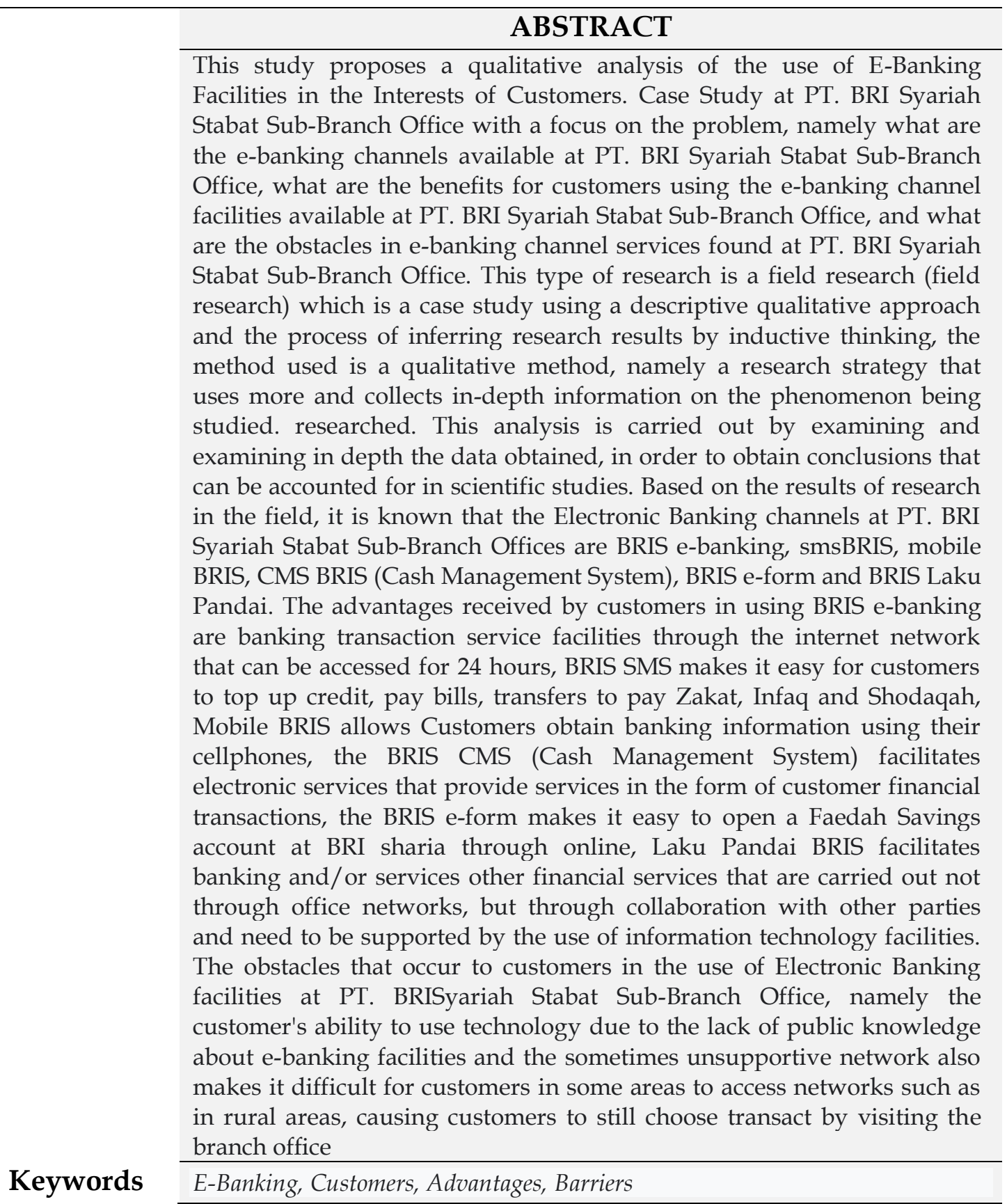




\section{PENDAHULUAN}

Dalam pembicaraan sehari-hari, bank dikenal sebagai lembaga keuangan yang kegiatan utamanya menerima simpanan giro, tabungan dan deposito. Kemudian bank juga dikenal sebagai tempat untuk meminjam uang bagi masyarakat yang membutuhkannya. Bank adalah usaha yang kekayaannya terutama dalam bentuk aset keuangan (Financial Assets) serta bermotifkan profit dan juga sosial, jadi bukan hanya mencari keuntungan saja (Hasibuan, 2008). Disamping itu, bank juga dikenal sebagai tempat untuk menukar uang, memindahkan uang atau menerima segala macam bentuk pembayaran dan setoran seperti pembayaran listrik, telepon, air, pajak dan sebagainya. Masyarakat kita tentunya sudah tidak asing lagi dengan berbagai macam kegiatan perbankan, terlebih lagi disaat krisis yang dilanda indonesia beberapa waktu lalu yang diikuti dengan bubarnya beberapa bank. Pengenalan bank dari sebagian masyarakat masih sebatas dalam artian yang sempit, padahal begitu banyak layanan bank yang dapat dinikmati oleh masyarakat saat ini seiring perkembangan zaman.

Berkaitan dengan sistem operasional bank, manajemen pada bank syariah tidak begitu banyak perbedaan dengan bank pada umumnya (bank konvensional). Akan tetapi dengan adanya landasan syariah serta sesuai dengan undang-undang yang menyangkut bank syariah terdapat perbedaan baik dari sisi organisasi maupun operasional, terutama adanya Dewan Pengawas Syariah (DPS) dalam struktur organisasi dan adanya sebuah sistem parbankan yang menerapkan bagi hasil (Muhammad, 2000).

Menyadari semakin ketatnya persaingan yang terjadi didunia bisnis, kualitas pelayanan perbankan semakin meningkat semakin kompleks pasca keluarnya penjamina terbatas (dana nasabah) yang dilakukan oleh Lembaga Penjamin Simpanan (LPS). Hal ini menjadikan setiap bank berusaha untuk terus berupaya meningkatkan kualitas pelayanannya agar kepuasan nasabah dapat terwujud. Sementara dari sisi produk, banyak bank menawarkan produk yang tak jauh berbeda. Salah satu hal yang menjadi pembeda antara bank yang satu dengan bank yang lainnya adalah dengan meningkatkan kualitas pelayanannya, sehingga dengan terus berupaya meningkatkan pelayanan mampu menarik minat nasabah dan berlangsungnya kegiatan perbankan.

Dalam upaya meningkatkan pelayanan tentunya dibutuhkan peran besar teknonolgi informasi guna mempermudah segala urusan nasabah dengan perbankan. Saat ini tingkat mobilitas dan kesibukan yang semakin meningkat mengakibatkan banyak orang membutuhkan suatu terobosan teknologi yang bisa dengan cepat dan tepat memenuhi kegiatan perbankannya. Pada era tahun 1990-an kita diperkenalkan dengan adanya sistem perbankan modern yaitu kita diperkenalkan dengan transaksi Automatic Teller Machine atau yang lebih sering disingkat dengan ATM. Namun kehadiran ATM saat ini masih dirasa ketinggalan, dimana orang harus mencari keberadaan ATM yang sesuai dengan bank dimana ia menyimpan uangnya.

Perkembangan teknologi informasi, telekomunikasi di dunia sudah berkembang sangat pesat dan internet merupakan salah satu perkembangan yang sangat menonjol, ini memungkinkan basis usaha saat ini menggunakan internet. Salah satu aplikasi 
yang mulai mendapat perhatian adalah internet banking sering juga disebut dengan $e$ Banking.

Fasilitas e-Banking dapat didefinisikan sebagai jasa pelayanan kapada nasabah untuk menikmati berbagai produk perbankan yang ditawarkan melalui perankat elaktronik. e-Banking memungkinkan nasabah baik individu maupun kelompok bisnis mengakses rekening, melakukan berbagai macam transaksi atau mendapatkan informasi produk perbankan dengan menggunakan teknologi internet melalui berbagai perangkat elektronik seperti komputer, laptop, PDA, maupun handphone (Rahardjo, 2001).

Saat ini banyak nasabah yang masih meragukan efektifitas bertransaksi lewat $e$ Banking, dikarenakan keamanan sistem yang masih menjadi salah satu faktor. Meskipun demikian tidak sedikit pula yang berani mencoba, bahkan saat ini bertransaksi menggunakan fasilitas e-Banking menjadi sesuatu yang sangat diperlukan. e-Banking merupakan sebuah terobosan baru dalam dunia perbankan saat ini, dimana nasabah tidak perlu lagi membuang banyak waktunya berada di bank hanya untuk melakukan transaksi, karena dengan hadirnya e-banking transaksi dapat dilakukan dimana saja dan kapan saja. Selain memudahkan para nasabah dalam melakukan transaksi, penggunaan fasilitas e-Banking juga sangat membantu meringankan tugas penyedia layanan perbankan.

Berdasarkan latar belakang yang telah diuraikan diatas penulis telah merumuskan permasalahan dalam penelitian ini, yaitu Apa saja saluran e-Banking yang terdapat pada PT BRI Syariah Kantor Cabang Pembantu Stabat?, Apakah keuntungan bagi nasabah, dalam penggunaan fasilitas e-Banking pada PT BRI Syariah Kantor Cabang Pembantu Stabat? Dan Apakah hambatan-hambatan dalam pelayanan pada fasilitas e-Banking PT BRI Syariah Kantor CabangPembatu Stabat?

Adapun yang menjadi tujuan pada penelitian ini adalah sebagai berikut: Agar dapat diketahui berbagai macam saluran e-Banking yang terdapat pada PT BRI Syariah Kantor Cabang Pembantu Stabat, Agar dapat diketahui keuntungan bagi nasabah, dalam penggunaan fasilitas e-Banking pada PT BRI Syariah Kantor Cabang Pembantu Stabat dan Agar dapat diketahui hambatan-hambatan dalam pelayanan pada fasilitas e-Banking PT BRI Syariah, beserta tindakan penanggulangannya.

Munculnya Electronic Banking itu sendiri tidak hanya berhubungan dengan bank saja, tetapi juga bekerja sama dengan operator selular. Sehingga dapat dilihat bahwa keberadaan Electronic Banking memberikan keuntungan kepada semua kalangan, seperti bank, operator selular dan nasabah bank pengguna Electronic Banking.

Ternyata $e$-Banking tersebut telah melahirkan beberapa produk, yaitu:

1. Internet Banking (via internet/komputer)

Internet Banking, ini termasuk saluran teranyar e-Banking yang memungkinkan nasabah melakukan transaksi via internet dengan menggunakan komputer/PC atau PDA. Fitur transaksi yang dapat dilakukan sama dengan Phone Banking yaitu informasi jasa/produk bank, informasi saldo rekening, transaksi pemindahbukuan antar rekening, pembayaran (kartu kredit, listrik, dan 
telepon), pembelian (voucher dan tiket), dan transfer ke bank lain. Kelebihan dari saluran ini adalah kenyamanan bertransaksi dengan tampilan menu dan informasi secara lengkap tertampang di layar computer/PC atau PDA (Saputro dan Sujadi, 2006).

2. Mobile Banking (via handphone)

Mobile Banking adalah layanan perbankan yang dapat diakses langsung melalui jaringantelepon seluler/handphone GSM (Global for Mobile Communication) atau CDMA dengan menggunakan layanan data yang telah disediakan oleh operator telepon seluler misal XL, Indosat, Telkomsel, dan operator telepon lainnya.

3. SMS Banking (via SMS)

SMS Banking, saluran ini pada dasarnya evolusi lebih lanjut dari Phone Banking, yang memungkinkan nasabah untuk bertransaksi via HP dengan perintah SMS. Fitur transaksi yang dapat dilakukan yaitu informasi saldo rekening, pemindahbukuan antar rekening, pembayaran (kartu kredit, listrik, dan telepon), dan pembelian voucher. Untuk transaksi lainnya pada dasarnya dapat pula dilakukan, namun tergantung pada akses yang dapat diberikan bank. Saluran ini sebenarnya termasuk praktis namun dalam prakteknya agak merepotkan karena nasabah harus menghapal kode-kode transaksi dalam pengetikan sms, kecuali pada bank yang melakukan kerjasama dengan operator seluler, menyediakan akses banking menu - Sim Tool Kit (STK) pada simcardnya.

4. Phone Banking (via telepon)

Phone Banking, ini adalah saluran yang memungkinkan nasabah untuk melakukan transaksi dengan bank via telepon. Pada awalnya lazim diakses melalui telepon rumah, namun seiring dengan makin populernya telepon genggam/HP, maka tersedia pula nomor akses khusus via HP bertarif panggilan flat dari manapun nasabah berada. Pada awalnya, layanan Phone Banking hanya bersifat informasi yaitu untuk informasi jasa/produk bank dan informasi saldo rekening serta dilayani oleh Customer Service Operator/CSO. Namun profilnya kemudian berkembang untuk transaksi pemindahbukuan antar rekening, pembayaran (kartu kredit, listrik, dan telepon), pembelian (voucher dan tiket), dan transfer ke bank lain; serta dilayani oleh Interactive Voice Response (IVR). Fasilitas ini boleh dibilang lebih praktis ketimbang ATM untuk transaksi non tunai, karena cukup menggunakan telepon/HP dimanapun kita berada, kita bisa melakukan berbagai transaksi, termasuk transfer ke bank lain.

5. ATM

ATM, Automated Teller Machine atau Anjungan Tunai Mandiri, ini adalah saluran E-Banking paling populer yang kita kenal. Setiap kita pasti mempunyai kartu ATM dan menggunakan fasilitas ATM. Fitur tradisional ATM adalah untuk mengetahui informasi saldo dan melakukan penarikan tunai. Dalam 
perkembangannya, fitur semakin bertambah yang memungkinkan untuk melakukan pemindahbukuan antar rekening, pembayaran (kartu kredit, listrik, dan telepon), pembelian (voucher dan tiket), dan yang terkini transfer ke bank lain (dalam satu switching jaringan ATM). Selain bertransaksi melalui mesin ATM, kartu ATM dapat pula digunakan untuk berbelanja ditempat perbelanjaan, berfungsi sebagai kartu debit. Bila kita mengenal ATM sebagai mesin untuk mengambil uang, belakangan muncul pula ATM yang dapat menerima setoran uang, yang dikenal pula sebagai Cash Deposit Machine/CDM. Layaklah bila ATM disebut sebagai mesin sejuta umat dan segala bisa, karena ragam fitur dan kemudahan penggunaannya.

Produk tersebut membuat lompatan teknologi yang luar biasa, menembus batasan ruang dan waktu. Kapanpun, dimanapun nasabah dapat bertransaksi selama 24 jam. Nasabah dibuat nyaman dengan produk jasa ini, karena untuk transaksi yang bermacam-macam cukup bertransaksi di tempat nasabah, dan tidak perlu datang ke bank.

Adapun Kelemahan Electronic Banking (E-Banking) adalah Resiko yang banyak terjadi adalah adanya orang atau sekelompok orang yang dengan sengaja melakukan kegiatan Phising. Artinya mereka membuat situs yang mirip dengan situs bank aslinya, sehingga tanpa disadari oleh nasabah bahwa yang bersangkutan sedang mengakses situs palsu karena logo bank dan formatnya sama persis menyerupai aslinya.

Pelaku phising akan mendapatkan informasi yang sangat rahasia; User Name dan nomor PIN. Dengan informasi lengkap ini mereka akan bebas bergerak memindahkan dana nasabah ke rekening mana yang mereka mau.

Untuk menjaga agar tidak masuk ke dalam perangkap ini, nasabah harus memasukkan alamat situs yang benar dan pasti. Jika tidak tahu jelas dan pasti, jangan mencoba-coba alamat situs yang belum pasti, Atau adanya sekelompok orang yang tidak bertanggung jawab mencoba untuk menggandeng mesin ATM dengan satu alat tambahan yang berfungsi untuk membaca data isi magnetik kartu ATM dan nomor PIN via camera.

\section{Penelitian Yang Relevan}

1. Dari penelitian Ami Wahyudi dengan analisis dan kajian teoritis terhadap penggunaa teknologi, maka akan berpengaruh dalam penurunan biaya operasional dan meningkatkan pelayanan, sehingga pelanggan akan mendapatkan kepuasan yang akan meningkatkan kepercayaan dalam bisnis.

2. Dari penelitian Edi Purwo Saputro, riset tentang kualitas jasa cenderung berkembang dan berbagai pendekatan metodologi yang dipakai juga mengalami transformasi yang lebih mengarah pada spesifikasi kasus untuk bidang jasa. Untuk kasus adopsi e-banking juga mengalami transformasi pendekatan metodologi servqual, BSQ dan ES-Qual.

3. Dari peneitian Budi Hermana, pengukuran kualitas layanan dengn menggunakan webqual yang terdiri dari empat variabel, yaitu usability, service interaction, information quality dan overall. Perilaku pengguna internet 
mempengaruhi persepsi kualitas layanan pada pada empat variabel tersebut. Empat variabel tersebut tidak bisa memprediksi secara akurat pengelompokan bank, dengan tingkat prediksi hanya sebesar 53\%. Hasil ini menunjukkan bahwa layanan e-banking di bank swasta cenderung tidak menujukkan perbedaan yang signifikan dengan layanan $e$-banking di bank pemerintah.

4. Dari penelitian Henny ediawaty, Farida, Ega Hegarini, Instrument penelitian untuk mengukur kualitas layanan e-banking yang disebarkan pada responden yang telah memenuhi kriteria dan akan diuji validitas dan rebilitasnya, sehingga dimensi yang dipilih dan dimensi yang baru dapat digunaka sebagai variabel pengukuran.

\section{METODE PENELITIAN}

Dalam penelitian ini, menggunakan jenis penelitian kualitatif dengan metode deskriptif. Data-data dikumpulkan, disusun, dikelompokkan, dianalisis, kemudian di integrasikan sehingga menjadi gambaran yang jelas dan terarah mengenai masalah yang diteliti. Merupakan metode penelitian yang dilaukan degan cara langsung terjun ke objek penelitian yang diteliti pada Bank BRI Syariah Kantor Cabang Pembantu Stabat.

Metode Pengumpulan data adalah Pengamatan (observasi), yakni melakukan pengamatan secara langsung pada objek yang diteliti dan Wawancara (interview), yakni melakukan tanya jawab dengan pihak-pihak yang berwenang dalam perusahaan tersebut untuk memperoleh keterangan yang berkaitan dengan penelitian. Adapun sumber data dilakukan dengan Data Primer adalah Data yang diperoleh secara langsung oleh penulis dari responden atau tempat penelitian yang dijadikan objek dari penelitian dan Data Sekunder adalah Data yang diperoleh melalui buku-buku atau literatur-literatur yang ada hubungannya dengan masalah yang diteliti. Data ini berupa landasan teori atau pedoman-pedoman lain yang berhubungan dengan permasalahan yang diteliti.

Teknik pengumpulan data adalah Penelitian terhadap suatu fenomena dapat dilakukan pada lingkungan yang natural maupun lingkungan buatan (artificial). Lingkungan studi penelitian ini adalah lingkungan natural, berupa studi lapangan (field study) yakni dengan mengambil informasi dari objek penelitian yaitu PT. BRISyariah kantor cabang pembantu Stabat.

Metode analisis data yang digunakan dalam penelitian ini adalah metode dalam bentuk deskriptif, dimana tujuannya dalam penelitian ini adalah untuk memberikan gambaran mengenai penelitian penulis tentang penggunaan fasilitas e-Banking dalam minat nasabah pada PT. BRISyariah kantor cabang pembantu Stabat.

\section{HASIL DAN PEMBAHASAN}

19 Desember 2007 dan setelah mendapatkan izin dari Bank Indonesia pada 16 Oktober 2008 melalui suratnya No.10/67/KEP.GBI/DpG/2008, maka pada tanggal 17 November 2008 PT. BRI Syariah secara resmi beroperasi. Kemudian PT. BRI Syariah 
merubah kegiatan usaha yang semula beroperasional secara konvensional, kemudian diubah menjadi kegiatan perbankan berdasarkan prinsip syariah Islam.

Dua tahun lebih PT. Bank BRIS yariah hadir mempersembahkan sebuah bank ritel modern terkemuka dengan layanan finansial sesuai kebutuhan nasabah dengan jangkauan termudah untuk kehidupan lebih bermakna. Melayani nasabah dengan pelayanan prima (service excellence) dan menawarkan beragam produk yang sesuai harapan nasabah dengan prinsip syariah.

Kehadiran PT. Bank BRI Syariah di tengah-tengah industry perbankan nasional dipertegas oleh makna pendar cahaya yang mengikuti logo perusahaan. Logo ini menggambarkan keinginan dan tuntutan masyarakat terhadap sebuah bank modern sekelas PT. Bank BRI Syariah yang mampu melayani masyarakat dalam kehidupan modern. Kombinasi warna yang digunakan merupakan turunan dari warna biru dan putih sebagai benang merah dengan brand PT. Bank Rakyat Indonesia (Persero), Tbk.

Aktivitas PT. Bank BRI Syariah semakin kokoh setelah pada 19 Desember 2008 ditandatangani akta pemisahan Unit Usaha Syariah PT. Bank Rakyat Indonesia (Persero), Tbk., untuk melebur kedalam PT. Bank BRI Syariah (proses spin off-) yang berlaku efektif pada tanggal 1 Januari 2009. Penandatanganan dilakukan oleh Bapak Sofyan Basir selaku Direktur Utama PT. Bank Rakyat Indonesia (Persero), Tbk., dan Bapak Ventje Rahardjo selaku Direktur Utama PT. Bank BRISyariah

Saat ini PT. Bank BRI Syariah menjadi bank syariah ketiga terbesar berdasarkan aset. PT. Bank BRI Syariah tumbuh dengan pesat baik dari sisi aset, jumlah pembiayaan dan perolehan dana pihak ketiga. Dengan berfokus pada segmen menengah bawah, PT. Bank BRI Syariah menargetkan menjadi bank ritel modern terkemuka dengan berbagai ragam produk dan layanan perbankan.

Sesuai dengan visinya, saat ini PT. Bank BRI Syariah merintis sinergi dengan PT. Bank Rakyat Indonesia (Persero), Tbk., dengan memanfaatkan jaringan kerja PT. Bank Rakyat Indonesia (Persero), Tbk., sebagai Kantor Layanan Syariah dalam mengembangkan bisnis yang berfokus kepada kegiatan penghimpunan dana masyarakat dan kegiatan consumer berdasarkan prinsip Syariah.

\section{E-banking BRIS}

Dalam lingkungan bisnis yang semakin kompleks dan bergerak dinamis, serta untuk menghemat waktu bagi pelaku bisnis, diperlukan solusi yang tepat untuk melakukan transaksi dengan Cepat, Aman dan Mudah. BRI Syariah hadir memberikan solusi bertransaksi dengan cepat, aman dan mudah, melalui Layanan Internet Banking BRIS.

Internet Banking BRI Syariah (Internet Banking BRIS) adalah fasilitas layanan transaksi perbankan melalui jaringan internet yang dapat diakses selama 24 jam, kapan dan dimanapun Nasabah berada menggunakan Personal Computer, Laptop, Notebook atau smartphone. Internet Banking BRIS akan memberikan Anda kemudahan, kepraktisan, keamanan serta kenyamanan bagi nasabah dalam melakukan transaksi secara online. Dengan layanan Internet Banking, transaksi dapat dilakukan dimana saja dan kapan saja, selama terdapat koneksi jaringan internet. 
Internet Banking BRIS membantu membantu nasabah dalam hal : Melakukan transaksi non finansial (spt: informasi saldo, mutasi rekening) dan transaksi finansial (spt: transfer Antar Rekening BRISyariah, transfer Online Antar Bank, Kliring SKN dan RTGS), Melakukan proses pembayaran tagihan bulanan dan transaksi pembelian kebutuhan Anda dan Keuntungan Menggunakan Layanan

Adapun Internet Banking BRIS antara lain: Hemat Waktu, karena Anda tidak perlu meninggalkan meja kerja Anda untuk melakukan aktivitas perbankan, cukup menggunakan PC, Laptop atau smartphone Anda yang telah terkoneksi dengan jaringan internet, Aman, dilengkapi sistem keamanan berlapis dengan dukungan keamanan jaringan SSL (Secure Socket Layer) bersertifikat Symantec 128 sd 256 bit serta mToken BRIS, Transaksi Real Time Online, karena dapat dilakukan kapanpun, dan dimanapun melalui jaringan internet dan Satu akses untuk semua produk, dengan login hanya menggunakan 1 User ID Anda dapat sekaligus mengakses seluruh rekening yang Anda miliki di BRI Syariah.

Fitur Layanan Yang Tersedia pada internet banking BRIS adalah Transaksi Non Finansial Informasi, Saldo Tabungan, Giro, dan Deposito, Mutasi (Rekening Koran), Rincian Pembiayaan, Riwayat Transaksi, Daftar Rekening Transfer, Manajemen Pengaturan Pengguna, Ubah, Password, Ubah No. Telepon Seluler, Ubah Email dan Kirim Ulang. Transaksi Finansial seperti Transfer Dana, Transfer Sesama Rekening BRISyariah, Transfer Online Antar Bank, SKN (Sistim Kliring Nasional) dan RTGS (Real Time Gross Settlement)

\section{SMS banking BRIS}

Dengan hanya mengetikkan SMS dan mengirimkan ke 3338, transaksi perbankan semakin mudah dilakukan kapan dan dimana saja. smsBRIS (SMSBanking BRIS) adalah fasilitas layanan perbankan bagi Nasabah Tabungan BRIS yang memudahkan Anda untuk melakukan isi ulang pulsa, bayar tagihan, transfer sampai pembayaran Zakat, Infaq danShodaqah. Mudah dan Fleksibel Transaksi perbankan dapat dilakukan kapan dan dimana saja, tidak tergantung dengan jam operasional Bank dan dapat diakses 24 jam. Lebih Efisien Tidak dikenakan biaya transaksi layanan (hanya dikenakan tariff SMS dari operator). Semua transaksi melalui SMSBanking BRIS secara real time dan online. Apapun jenis SIM Card yang Anda miliki, transaksi perbankan dapat Anda lakukan. Adapun transaksi yang terdapat pada sms banking BRIS antara lain:

1. Transaksi Non Finansial seperti Inquiry Saldo, Inquiry Mutasi 3 transaksi terakhir, Inquiry tagihan Telepon, Inquiry Flexy Postpaid, Inquiry Speedy, Inquiry Telkomvision, Inquiry Kartu HALO, Ganti PIN, Informasi NISBAH, Fasilitas bantuan (HELP) bagi User untuk mengetahui, format perintah transaksi (syntax message) SMSBanking BRIS, Inquiry Tagihan PLN, Inquiry Tagihan PLN Non Taglist (tambah daya, pasang baru, dsb)

2. Transaksi Finansial

3. Transfer antar rekening BRI Syariah seperti Isi Ulang Pulsa, Transfer Antar Bank dan Pembayaran Tagihan 


\section{Mobile BRIS}

MobileBRIS adalah layanan yang memungkinkan Nasabah memperoleh informasi perbankan dan melakukan komunikasi serta transaksi perbankan melalui perangkat yang bersifat mobile seperti telepon seluler/handphone menggunakan media menu pada aplikasi mobile BRIS dengan menggunakan media jaringan internet pada handphone yang dikombinasikan dengan media Short Message Service (SMS) secara aman dan mudah. Nasabah yang ingin menggunakan fasilitas mobileBRIS dapat melakukan registrasi SMS Banking terlebih dahulu. Jenis Transaksi mobile BRIS:

1. Transaksi non-finansial: Informasi Saldo, Informasi Mutasi 3 Transaksi Terakhir, Ganti PIN, Cek history transaksi (inbox aplikasi) dan Daftar Transaksi Favorit

2. Transaksi Finansial: Transfer sesama rekening BRI SyaiahTransfer Antar Bank, Pembayaran Tagihan PLN, Pembayaran PLN Non Tagihan Listrik, Pembayaran Tagihan Telepon (TELKOM), Pembayaran Telkom Flexi, Pembayaran Kartu HALO Telkomsel, Pembayaran XL Postpaid, Pembayaran Smartfren Postpaid, Pembayaran Speedy, Pembayaran Transivision, Pembayaran BIG TV, Pembayaran Indovision, Pembayaran Donasi (BAZNAS, Dompet Dhuafa, Gria Yatim, ZIS BRISyariah, BAZIS DKI Jakarta, Yayasan Dompet Sosial Madani Bali, Yayasan Baitul Maal Hidayatullah, Rumah Zakat, LazisNU Jatim)Pembayaran Institusi (Khadijah Surabaya, UNISBA, Univ. Aisyitah Yogyakarta, SD Al Muttaqin, UIN Suska Riau, Univ. Syiah Kuala Aceh, Al Irsyad Purwokerto, Panca Budi Medan, Universitas Riau, Universitas Malikussaleh, Yayasan Al Falah Jambi, IAIN Salatiga, Al Furqan Jember, UMSU, UIN Walisongo, IAIN Purwokerto, IAIN Palu, UIN Sumatera Utara, Yay. Al Kautsar, Poltek Indonusa Surakarta, SMAM 1 Gresik, STEMBI, SD Muh. Manyar Gresik, SMK Riksa Indrya, Stikes BTH Tasikmalaya, UIN Sunan Gunung Djati, Ulil Albab Batam, Universitas Jember, IAIN Samarinda, IAIN Surakarta, UM Metro Lampung, dll) Pembelian PLN Prepaid (Token), Pembelian Pulsa Telkomsel, Pembelian Pulsa Indosat, Pembelian Pulsa XL, Pembelian Pulsa Smartfren, Pembelian Paket Internet Telkomsel, Pembelian BIG TV dan Top Up Gopay Gojek.

\section{CMS BRIS ( Cash Management System )}

Salah satu produk unggulan BRISyariah, dalam rangka mengusung visinya sebagai bank ritel modern terkemuka, adalah Cash Management BRISyariah iB (CMS). Produk yang disegmentasikan bagi nasabah korporat ini memberikan solusi terbaik dalam rangka pengelolaan keuangan dan monitoring arus kas korporat. Didukung dengan teknologi mutakhir, sistem pengamanan yang maksimal, serta pelayanan yang prima, CMS BRISyariah iB diharapkan mampu memberikan solusi terbaik bagi nasabah segmen korporat.

Saat ini terdapat perusahaan-perusahaan, institusi-institusi serta badan usaha yang telah menggunakan jasa layanan CMS BRISyariah iB dengan sukses dan berjalan dengan lancar. CMS BRISyariah iB bahkan saat ini telah dapat mengakomodasikan 
kebutuhan akan data transaksi yang cepat dan akurat, sehingga menjadikan layanan ini semakin terpadu dan berkualitas

CMS BRISyariah iB sebagai layanan elektronik yang menyajikan layanan berupa transaksi finansial, antara lain transfer antar rekening BRISyariah atau ke rekening bank lain, electronic payroll systems, pembayaran tagihan hingga sistem laporan pembayaran dan non fi $\neg$ nansial (informasi saldo, laporan historis transaksi, dan download sebagai media penyajian laporan keuangan). Fitur Layanan CMS BRIS :

1. Transaksi Non Finansial : Non Financial Transaction (layanan non finansial), Account Informational Base (informasi rekening), Balance Inquiry (informasi saldo rekening) dan Historical Transaction Report (informasi mutasi transaksi).

2. Transaksi Finansial : Fitur Basic Cash Management, Transfer antar rekening BRISyariah, Transfer antar Bank via SKN/RTGS/ATM Bersama/Prima,Electronic Payroll System, Billpayment System - PLN dan Liquidity Management.

\section{Keuntungan Bagi Nasabah Dalam Penggunaan Fasilitas Electronic Banking Pada PT. BRI Syariah KCP Stabat}

Dengan memanfaatkan E-Banking, banyak keuntungan yang akan diperoleh nasabah terutama apabila dilihat dari banyaknya waktu dan tenaga yang dapat dihemat karena E-Banking jelas bebas antrian dan dapat dilakukan darimana saja sepanjang nasabah memiliki sarana pendukung untuk melakukan layanan E-Banking tersebut. Fungsi penggunaannya mirip dengan mesin ATM dimana sarananya saja yang berbeda, seorang nasabah dapat melakukan aktifitas pengecekan saldo rekening, transfer dana antar rekening atau antar bank, hingga pembayaran tagihan-tagihan rutin bulanan seperti: listrik, telepon, kartu kredit, dll. Dengan memanfaatkan ebanking banyak keuntungan yang akan diperoleh nasabah terutama apabila dilihat dari banyaknya waktu dan tenaga yang dapat dihemat karena e-banking jelas bebas antrian dan dapat dilakukan dari mana saja sepanjang nasabah memiliki sarana pendukung untuk melakukan layanan e-banking tersebut.

\section{Hambatan-Hambatan Dalam Penggunaan Fasilitas Electronic Banking Pada PT. BRI Syariah KCP Stabat}

Transaksi Internet Banking (e-banking) bukan hanya mempermudah tetapi dapat menimbulkan suatu resiko seperti strategi, operasional, dan reputasi serta adanya berbagai ancaman terhadap aliran data realible dan ancaman kerusakan / kegagalan terhadap sistem Internet Banking kemudian semakin kompleksnya teknologi yang menjadi dasar Internet Banking. Namun, masyarakat pada umumnya juga memiliki hambatan-hambatan dalam penggunaan fasilitas E-Banking, seperti nasabah pada Bank Muamalat. Berikut hambatan-hambatan yang terjadi pada nasabah Bank Muamalat dalam penggunaan fasilitas e-Muamalat, yaitu :

1. Kemampuan nasabah tentang penggunaan teknologi. Kurangnya ilmu pengetahuan masyarakat tentang fasilitas e-banking sehingga masih banyak yang tidak mengerti dalam penggunaan teknologi (Gaptek). Nasabah sering bertanya kepada customer service karena ketidakpahaman mereka dalam 
penggunaan aplikasi pada ponsel dalam melakukan transaksi melalui $e$ Muamalat sehingga para nasabah masih saja memilih bertransaksi dengan cara mendatangi kantor cabang.

2. Jaringan yang harus sesuai dengan provider. Sering terjadi nasabah pada umumnya memiliki hambatan dalam menggunakan fasilitas e-banking. Nasabah yang berada di daerah sulit untuk mengakses jaringan seperti di pedesaan, maka secara otomatis jaringannya akan terganggu. Hal tersebut yang menyebabkan nasabah pada Bank Muamalat lebih memilih untuk tidak menggunakan aplikasi e-Mumalat yang mampu menghambat segala aktivitas bertransaksi secara manual dan dapat beresiko seperti cybercrime.

3. Pemerintah bersama DPR (periode manapun) sampai saat ini masih terkesan sangatlambat dalam melakukan antisipasi terhadap maraknya kejahatan yang terjadi melaluikegiatan Internet Banking.

4. Kegiatan Internet Banking masih belum memiliki payung hukum yang akurat dan tegasyang disebabkan oleh masih stagnannya RUU Informasi dan Transaksi Elektronik.

5. Para pelaku usaha (perbankan) dan masyarakat pada umumnya masih kurang peduliterhadap proses penanganan kasus-kasus tindak Pidana Internet Banking

6. Untuk mengantisipasi berbagai permasalahan yang terkait dengan keamanan sistem informasi,maka perlu diimplementasikan suatu kebijakan dan prosedur pengamanan yang mencakup :

a. Identifikasi sumber-sumber dan aset-aset yang akan dilindungi

b. Analisa kemungkinan ancaman dan konsekuensinya

c. Perkirakan biaya atau kerugian-kerugian yang dapat ditimbulkan

d. Analisa potensi tindakan penangkal dan biayanya serta kerugian lainnya

e. Mekanisme pengamanan yang sesuai

f. Perlu adanya suatu ketentuan yang mengatur perbankan nasional yang memiliki pusat penyimpanan, pemrosesan data atau informasi dan transaksi perbankan yang letaknya diluar negeri

g. Perlu dibentuk sebuah unit kerja khusus atau divisi Pengamanan Pencegahan kejahatan perbankan di dalam struktur Bank / Bank Indonesia yang fungsinya untuk melakukan penerapan kebijakan pengamanan sistem, melakukan penelitian untuk pencegahanterhadap ancaman / kejahatan yang sudah ada maupun yang mungkin terjadi danmelakukan tindakan recovery serta pemantauan transaksi perbankan selama 24 jam

h. Bank Indonesia perlu melakukan audit terhadap sistem teknologi informasi dankomunikasi yang dilakukan oleh perbankan untuk setiap kurun waktu tertentu 
i. Memperketat / mengendalikan dengan cermat akses nasabah maupun pegawai kejaringansistem ICT perbankan, agar seluruh pegawai perbankan mengetahui bahwa mereka juga dipantau

j. Perlu adanya ketentuan (Peraturan atau UU) agar perbankan bertanggung jawab denganmengganti uang nasabah yang hilang akibat kelemahan sistem pengamanan ICT perbankan

k. Perlu digunakan Perangkat Lunak Komputer Deteksi (software) untuk aktifitas rekeningnasabah agar apabila terjadi kejanggalan transaksi dapat ditangani dengan cepat

1. Perlu sosialisasi aktif dari perbankan kepada masyarakat / nasabah dan pegawaiperbankan mengenai bentuk-bentuk kejahatan yang dapat terjadi dengan produk / layanan yang disediakannya

m. Menambah persyaratan formulir identitas pada waktu pembukaan rekening baru untuk pemeriksaan pada data base yang menghimpun daftar orang bermasalah dengan institusi keuangan

\section{KESIMPULAN}

Setelah melakukan pembahasan dalam penulisan ini, berdasarkan analisis baik secara teoritis maupun kesimpulan berdasarkan praktik di lapangan, maka penulis mengambil beberapa kesimpulan, yaitu : Saluran-saluran Electronic Banking pada PT. BRI Syariah Kantor Cabang Pembantu Stabat adalah e-banking BRIS, smsBRIS, mobile BRIS, CMS BRIS ( Cash Management System ), e-form BRIS dan Laku Pandai BRIS. ebanking BRIS adalah fasilitas layanan transaksi perbankan melalui jaringan internet yang dapat diakses selama 24 jam, kapan dan dimanapun nasabah berada menggunakan Personal Computer, Laptop, Notebook atau smartphone. SMS BRIS fasilitas layanan perbankan bagi Nasabah Tabungan BRIS yang memudahkan Anda untuk melakukan isi ulang pulsa, bayar tagihan, transfer sampai pembayaran Zakat, Infaq dan Shodaqah. Mobile BRIS adalah layanan yang memungkinkan Nasabah memperoleh informasi perbankan dan melakukan komunikasi serta transaksi perbankan melalui perangkat yang bersifat mobile seperti telepon seluler/handphone menggunakan media menu pada aplikasi mobileBRIS dengan menggunakan media jaringan internet pada handphone yang dikombinasikan dengan media Short Message Service (SMS) secara aman dan mudah. CMS BRIS ( Cash Management System ) adalah layanan elektronik yang menyajikan layanan berupa transaksi finansial, antara lain transfer antar rekening BRISyariah atau ke rekening bank lain, electronic payroll systems, pembayaran tagihan hingga sistem laporan pembayaran dan non fi $\neg$ nansial (informasi saldo, laporan historis transaksi, dan download sebagai media penyajian laporan keuangan).

e-form BRIS adalah layanan untuk membuka rekening Tabungan Faedah di BRIsyariah cukup melakukan input data Anda di website BRIsyariah,kemudian datang ke Cabang BRIsyariah terdekat, maka proses pembukaan rekening akan di proses dengan cepat. Laku Pandai BRIS merupakan kegiatan BRISyariah untuk 
menyediakan layanan perbankan dan/atau layanan keuangan lainnya yang dilakukan tidak melalui jaringan kantor, namun melalui kerjasama dengan pihak lain dan perlu didukung dengan penggunaan sarana teknologi informasi. Hambatan-hambatan yang terjadi pada nasabah dalam penggunaan fasilitas Electronic Banking pada PT. BRI Syariah Kantor Cabang Pembantu Stabat yaitu pada kemampuan nasabah tentang penggunaan teknologi dikarenakan kurangnya ilmu pengetahuan masyarakat tentang fasilitas e-banking sehingga masih banyak yang tidak mengerti dalam penggunaan teknologi yang menyebabkan para nasabah masih saja memilih bertransaksi dengan cara mendatangi kantor cabang. Jaringan yang terkadang kurang mendukung juga mengakibatkan nasabah yang berada di beberapa daerah sulit untuk mengakses jaringan seperti di pedesaan, maka secara otomatis jaringannya akan terganggu sehingga nasabah pada PT. BRISyariah Kantor Cabang Pembantu Stabat lebih memilih untuk tidak menggunakan aplikasi electronic baking yang mampu menghambat segala aktivitas bertransaksi nasabah.

Adapun saran dalam penelitian ini adalah dengan berkembangnya E-Banking di Indonesia dan beragamnya kemudahan transaksi E-Banking, kita harus bisa memanfaatkannya dengan bijak. Saat menggunakan E-Banking seharusnya berhatihati, jangan sampai manfaat dari E-Banking tersebut diambil oleh orang lain, seperti tindak kejahatan yang ada. Bagi masyarakat atau nasabah PT. BRI Syariah Kantor Cabang Pembantu Stabat yang belum terdaftar untuk menggunakan E-Banking penulis menyarankan agar untuk segera mendaftar, karena E-Banking sangat memudahkan nasabah dalam bertransaksi finansial maupun non finansial. Apalagi untuk nasabah yang memiliki tingkat kegiatan atau kesibukan yang padat, E-Banking bisa menjadi alternatif agar bisa bertransaksi kapan dan dimanapun nasabah berada tanpa harus perlu datang langsung ke bank.

\section{DAFTAR PUSTAKA}

Al-Qur'anul Kari

Abdullah, Ma'ruf. Hukum Perbankan dan Perkembangan Bank Syariah di Indonesia. Banjarmasin: Antasari Press. 2006.

Anshori, Abdul Gofur. Hukum Perbankan Syariah. Bandung : Refika Aditama. 2009. Hasan, Alwi. Kamus Umum Bahasa Indonesia. Jakarta : Balai Pustaka. 2007.

Hasibuan, Malayu. Dasar-Dasar Perbankan. Jakarta : Bumi Aksara. 2008.

Ifham, Ahmad. Ini Lho Bank Syariah. Jakarta : PT. Gramedia Pustaka Utama. 2015.

Ikatan Bankir Indonesia, Memahami Bisnis Bank Syariah. Jakarta : Gramedia Pustaka Utama. 2014.

Ismail. Manajemen Perbankan. Jakarta: PRENADAMEDIA GROUP. 2016.

Ismail. Manajemen Perbankan : Dari Teori Menuju Aplikasi. Jakarta : Kencana. 2010.

Ismail, Perbankan Syariah. Jakarta : Penerbit Kencana Prenada Media Group. 2013.

Jasfar, Farida. Manajemen Jasa Terpadu. Jakarta : Ghalia Indonesia. 2009.

Karim, Adiwarman. Bank Islam : Analisis Fiqih dan Keuangan. Jakarta: Rajawali Pers. 2009. 
Journal Economy And Currency Study (JECS)

Volume 3, Issue 2, July 2021

Page 10-23

Kasmir. Bank dan Lembaga Keuangan Lainnya. Jakarta : PT Raja Grafindo Persada. 2014.

Kasmir. Dasar-Dasar Perbankan. Jakarta : Rajawali Pers. 2013.

Kasmir. Manajemen Perbankan. Jakarta : Raja Grafindo Persada. 2006.

Muktar, Bustari. Bank dan Lembaga Keuangan Lain. Jakarta : Prenada Media. 2016.

Muhammad. Sistem dan Prosedur Operasional Perbankan Syariah. Yogyakarta : UII Press. 2000.

Nasution, Nur. Manajemen Jasa Terpadu. Bogor Selatan : Ghalia Indonesia, 2009.

Nurastuti, Wiji. Teknologi Perbankan. Yogyakarta : Graha Ilmu. 2011.

Rahardjo, Budi. Aspek Teknologi dan Keamanan dalam Internet Banking. Jakarta : PT Insan Indonesia. 2001.

Sholihin, Ahmad Ifham. Buku Pintar Ekonomi Syariah. Jakarta : PT Gramedia Pustaka Utama. 2010.

Siswandi. Banking ENon-Banking Practice. Jakarta : Mitra Wacana Media. 2008.

Sujadi dan Edi Purwo Saputro. E-Banking: Urgensi Aspek Trust di Era E-Service. Jakarta : Raja Grafindo. 2006.

Sulaiman, Abdul Wahab Ibrahim Abu. Banking Cards Syariah: Kartu Kredit dan Debit dalam Perspektif Fiqih. Jakarta : Raja Grafindo Persada. 2006.

Supriyono, Maryanto. Buku Pintar Perbankan. Yogyakarta : ANDI. 2011.

Syakir, Ahmad. Diktat : Perbankan Syariah. Medan : IAIN SU : 2013.

Undang-Undang Nomor 21 Tahun 2008 Tentang Perbankan Syariah.

Veithzal Rivai dan Rifki Ismail. Islamic Risk Management for Islamic Bank. Jakarta : Gramedia Pustaka Utama. 2013.

\section{Sumber Internet :}

http://dirablog17.blogspot.com/2012/03/makalah-e-banking.html. Diakses 06 September 2017 pukul $10: 00 \mathrm{wib}$

http://www.brisyariah.co.id/?q=sejarah. Diakses 10 Desember 2017 pukul 13 :00 wib. hhtp://www.brisyariah.co.id/?q=visidanmisi. Diakses 10 Desember 2017 pukul $13: 30$ wib. 